\section{Comparison of the characteristics and injury severity of passengers in motor vehicle accidents between urban and rural cities in South Korea}

\author{
Jae Yeon Park, Ho Jung Kim, Hyo Jung Choi \\ Department of Emergency Medicine, Soonchunhyang University Bucheon Hospital, Bucheon, Korea
}

Objective To analyze motor vehicle accidents in two different traffic environments and compare differences in severity between both regions.

Methods Injury data were collected by the Emergency Medicine and Traffic Accident Research Team as part of the Korean In-Depth Accident Study. Patients admitted to emergency medical centers located in Wonju, Gangwon province (population 345,143, rural, group A) and Bucheon, Gyeonggi province (population 870,735, urban, group B) between January 2011 and December 2017 were included for analysis. Injury severity was classified into four categories based on Injury Severity Score (ISS): minor $(1 \leq<9)$, moderate $(9 \leq<15)$, major $(15 \leq<25)$, and critical $(\geq 25)$.

Results Overall, 1,807 patients were included (group A, 1,484; group B, 323). There was a higher proportion of daytime accidents, accidents involving larger cars, passenger injuries, and accidents involving lack of seat belt use in group $A$ than in group $B$. The mean ISS value was 8.98 in group $A$ and 4.62 in group $B(P<0.001)$. Minor $(20.4 \%$ vs. $10.8 \%)$ and major/critical $(15.7 \%$ vs. $5.0 \%)$ injuries were more frequent in group $A$ than group $B(P<0.001)$. Patient ratios $(A / B)$ for each ISS classification were 0.76 (minor), 1.89 (moderate), 3.43 (major), and 2.77 (critical). The factors showing a significant relationship with severity were driver's seat $(P=0.037)$ and no seat belt $(\mathrm{P}<0.001)$.

Conclusion Patients in a rural city who visited the emergency room owing to motor vehicle accidents had more severe injuries than those in an urban city.

Keywords Accidents, traffic; Injury Severity Score; Geography, medical; Risk factors

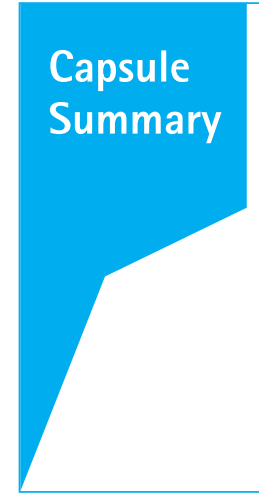

What is already known

There are more traffic accidents and more deaths in rural areas than in urban areas. Overall, only statistical data on end-effects, such as mortality, were reported.

What is new in the current study

We analyzed in-depth traffic accident personal injury data from the Korean InDepth Accident Study, and conducted a clinical analysis of injury severity. Injuries were more severe in the rural city where fewer people wore seat belts.
eISSN: 2383-4625

Received: 5 May 2019

Revised: 18 June 2019

Accepted: 1 July 2019

Correspondence to: Jae Yeon Park Department of Emergency Medicine, Soonchunhyang University Bucheon Hospital, 170 Jomaru-ro, Wonmi-gu, Bucheon 14584, Korea

E-mail: t0460@schmc.ac.kr ORCID

http://orcid.org/0000-0003-0256-9359

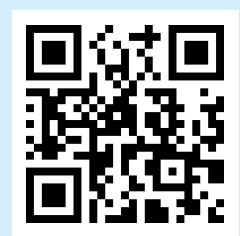

How to cite this article:

Park JY, Kim HJ, Choi HJ. Comparison of the characteristics and injury severity of passengers in motor vehicle accidents between urban and rural cities in South Korea. Clin Exp Emerg Med 2020;7(1):30-34.

This is an Open Access article distributed under the terms of the Creative Commons Attribution Non-Commercial License (https:// creativecommons.org/licenses/by-nc/4.0/). 


\section{INTRODUCTION}

Although traffic accidents are declining in South Korea, the death rate caused by traffic accidents is still high. At 8.1 per 100,000, it is higher than the Organization for Economic Cooperation and Development average of 5.3 in 2014. ${ }^{1}$ The introduction of legislation that restricts drunk and unauthorized driving has led to a decrease in traffic accidents. In addition, the development of safety devices for vehicles is an important factor in reducing the severity of injuries caused by accidents. ${ }^{2,3}$ Internationally, such data on accidents are collected by the National Automotive Sampling System/Crashworthiness Data System and Crash Injury Research and Engineering Network of the National Highway Traffic Safety Administration in the United States, and the German InDepth Accident Study in Germany. These data enable the in-depth review of more specific injuries. ${ }^{4}$ In Korea, the recently introduced Korean In-Depth Accident Study (KIDAS) has facilitated such studies. $^{5-7}$ Adequate reviews for understanding the characteristics and merits of safety devices for vehicles were previously impossible due to a lack of cooperation among different companies and a lack of technical knowledge. However, with the introduction of the KIDAS, the accumulation of accident data is improving. It is possible to compare more accident factors than just differences in mortality. A recently conducted yet limited survey of traffic accidents in Korea identified regional differences in mortality, which was twice as high in rural areas than that in the suburbs of Seoul. ${ }^{8}$ Because the mortality rate depends on both the frequency of accidents and the treatment after an accident, it is difficult to make inter-regional comparisons of the severity of actual accidents. Many variables reflect regional differences and must also be considered. ${ }^{9}$ In order to analyze the severity of human injuries, it is essential to study the specific factors affecting the injuries. Therefore, this study aimed to compare the KIDAS data between two regions with different populations and geographical locations and investigate the general characteristics and severity of specific injuries rather than just mortality. This is the first study of its kind comparing the injury severity of traffic accident victims between rural and urban areas in Korea using in-depth measures of injury severity and accident characteristics.

\section{METHODS}

\section{Study setting and population}

This study evaluated patients who visited emergency departments (EDs) between January 2011 and December 2017. To compare regional characteristics, the patients who visited an emergency medical center in Wonju, Gangwon province (population 345,143 in
2019, annual ED visit number 50,000), a rural area, were classified as group $A$, and those who visited an emergency medical center located in Bucheon, Gyeonggi province (population 870,735 in 2019, annual ED visit number 60,000), an urban area, as group B.

\section{Data}

Human injury data were collected by the Emergency Medicine and Traffic Accident Research Team as part of the KIDAS. The data collected included demographic characteristics such as age, sex, height, and weight, and passenger characteristics such as accident time, vehicle type, seating position, use of seat belts, and cases of drunk driving. The original KIDAS database was constructed following approval from the research ethics committee of Yonsei University (YWMR-14-5-074).

The accident time was divided into day (7:00 to 19:00) and night (19:00 to 7:00), when the traffic volume is generally lighter. The vehicles were classified into groups 1 (passenger cars and Sports Utility Vehicles [SUVs]), 2 (vans and light trucks), and 3 (buses and heavy trucks).

\section{Abbreviated Injury Score and Injury Severity Score}

Abbreviated Injury Score (AIS) is a simple impairment scale established by the American Association for the Advancement of Medicine. It is a useful measure for the injury severity of traffic accident victims. AIS divides the body into 9 areas and scales the severity of injury in each area from 1 to 6 points. The Injury Severity Score (ISS) was developed in 1974 as an improvement over AIS, and is most commonly used for classification of the severity of anatomical indices. After the classification of injuries using AIS, Only the highest AIS score in each body region is used. The 3 most severely injured body regions have their score squared and added together to produce the ISS score.

$$
I S S=A I S(1)^{2}+A I S(2)^{2}+A I S(3)^{2}
$$

Each ISS value is calculated from a minimum of 1 point to a maximum of 75 points. $^{10}$

ISS scores were then classified into four categories: minor, moderate, major, and critical (Table 1). ${ }^{11,12}$ This study is based on AIS 2005: update 2008.

\section{Analysis}

Statistical analysis was performed using IBM SPSS Statistics ver. 20.0 (IBM Corp., Armonk, NY, USA). A P-value $<0.05$ was considered statistically significant in all statistical tests. In the case of numerical variables, the mean \pm standard deviation was used, while in the case of categorical data, the frequency was expressed as a percentage. P-values were derived by Student's t-test or Mann- 
Table 1. Classifications of severity based on ISS

\begin{tabular}{ll}
\hline ISS & Classification \\
\hline $1 \leq$ ISS $<9$ & Minor injury \\
$9 \leq$ ISS $<15$ & Moderate injury \\
$15 \leq$ ISS $<25$ & Major injury \\
$25 \leq$ ISS & Critical injury
\end{tabular}

ISS, Injury Severity Score.

Table 2. Comparison of the general characteristics of traffic accident patients by region

\begin{tabular}{lccc}
\hline Variable & $\begin{array}{c}\text { Group A (rural) } \\
(\mathrm{n}=1,484)\end{array}$ & $\begin{array}{c}\text { Group B (urban) } \\
(\mathrm{n}=323)\end{array}$ & P-value \\
\hline Sex & & & 0.661 \\
$\quad$ Male & $904(60.9)$ & $201(62.2)$ & \\
$\quad$ Female & $580(39.1)$ & $122(37.8)$ & \\
Age $^{\text {a) }}$ & $43.3 \pm 18.51$ & $41.3 \pm 15.72$ & 0.081 \\
Height $^{\text {a) }}$ & $165.5 \pm 13.05$ & $165.1 \pm 15.20$ & 0.706 \\
Weight $^{\text {a) }}$ & $64.3 \pm 16.92$ & $64.4 \pm 15.98$ & 0.910 \\
\hline
\end{tabular}

Values are presented as number (\%) or mean \pm standard deviation.

a) Unknown: age $(B, n=87)$, height $(A, n=627 ; B, n=3)$, weight $(A, n=591 ; B, n=2)$.

Whitney U-test for numerical data, and by chi-squared test or Fisher exact test for categorical data. Linear multiple regression analysis was used to analyze the variables affecting ISS.

\section{RESULTS}

\section{Demographic and passenger characteristics}

The study enrolled 1,807 subjects: 1,484 in group A and 323 in group B. In both groups/regions, there were more males than females, but there was no significant gender difference between the two groups $(P=0.661)$. The average age in group $A$ was 2 years older than in group $B$, but this difference was not significant $(P=0.081)$. There were no significant differences in height or weight between the two groups (Table 2).

More patients presented during the day in group $A(59.5 \%)$ than in group $B(51.8 \%)(P=0.013)$. In both regions, the majority of patients were in smaller vehicles. In group $B, 80.7 \%$ of the patients were in group 1 vehicles versus $72.6 \%$ in group $A$. The rate of larger vehicle accidents (involving group 2 and group 3 vehicles) was significantly higher in group $A(P=0.010)$. In both regions, patients who presented were most likely to have been in the driver's seats, and less likely to have been in the passenger seats or other seats. There were more passenger-seat and otherseat patients in group $A$ than in group $B(P=0.013)$. In both regions, more patients were wearing seat belts than not, although the proportion of patients wearing seat belts was significantly higher in group $B(83.1 \%)$ than in group $A(56.4 \%)(P<0.001)$
Table 3. Comparison of traffic accident passenger characteristics by region

\begin{tabular}{|c|c|c|c|}
\hline Variable & $\begin{array}{l}\text { Group A (rural) } \\
\quad(n=1,484)\end{array}$ & $\begin{array}{l}\text { Group B (urban) } \\
\quad(n=323)\end{array}$ & P-value \\
\hline Time $e^{a)}$ & & & 0.013 \\
\hline Day & 889 (59.9) & 142 (51.8) & \\
\hline Night & $595(40.1)$ & $132(48.2)$ & \\
\hline Car type $e^{a)}$ & & & 0.010 \\
\hline Group $1^{\text {b) }}$ & $1,078(72.6)$ & $260(80.7)$ & \\
\hline Group $2^{\text {b) }}$ & 353 (23.8) & $55(17.1)$ & \\
\hline Group $3^{\text {b) }}$ & $53(3.6)$ & $7(2.2)$ & \\
\hline Seat location & & & 0.013 \\
\hline Driver & $870(59.9)$ & $222(68.7)$ & \\
\hline Assistant & $320(22.0)$ & $56(17.3)$ & \\
\hline Others & $263(18.1)$ & 45 (13.9) & \\
\hline Seat belt ${ }^{a)}$ & & & $<0.001$ \\
\hline Restrained & $755(56.4)$ & $246(83.1)$ & \\
\hline Not restrained & $548(43.6)$ & 50 (16.9) & \\
\hline Drink driving ${ }^{a)}$ & & & 0.171 \\
\hline Drunk & $123(10.2)$ & $6(5.8)$ & \\
\hline Not drunk & 1,087 (89.8) & 98 (94.2) & \\
\hline
\end{tabular}

Values are presented as number (\%).

a) Unknown: time $(B, n=49)$, car type $(A, n=1)$, seat belt $(A, n=145 ; B, n=27)$, drink driving $(A, n=274 ; B, n=219) .{ }^{b}$ Group 1 , sedan and sport utility vehicle; group 2, light truck and van; group 3, bus, middle truck, and heavy truck.

Table 4. Comparison of seat belt restraint rate by seat location in two regions

\begin{tabular}{llccc}
\hline Seat location & Seat belt & $\begin{array}{c}\text { Group A (rural) } \\
(\mathrm{n}=1,321)\end{array}$ & $\begin{array}{c}\text { Group B (urban) } \\
(\mathrm{n}=296)\end{array}$ & P-value \\
\hline Driver & Restrained & $532(65.4)$ & $184(90.6)$ & $<0.001$ \\
& Not restrained & $281(34.6)$ & $19(9.4)$ & \\
\multirow{2}{*}{ Assistant } & Restrained & $151(53.2)$ & $41(82.0)$ & $<0.001$ \\
& Not restrained & $133(46.8)$ & $9(18.0)$ & \\
\multirow{2}{*}{ Others } & Restrained & $69(30.8)$ & $31(48.8)$ & 0.024 \\
& Not restrained & $155(69.2)$ & $22(51.2)$ & \\
\end{tabular}

Values are presented as number (\%).

(Table 3). The rate of seat belt use was higher in group $B$ than group A for those in the driver's seat, the passenger's seat and other seats at the time of the initial accident (Table 4). There was no significant difference $(P=0.171)$ in the percentage of drunk drivers between the two regions.

\section{Comparison of injury severity between the two regions}

The mean ISS of the patients was twice as high in group A ( $8.98 \pm$ $12.19)$ as it was in group $B(4.62 \pm 8.30)(P<0.001)$, with a greater proportion of minor injury patients in group $B(84.2 \%)$ than in group A (63.9\%). Moderate injuries were twice as common in group A $(20.4 \%$ vs. $10.8 \%)$, whereas major and severe injuries were three times more common in group $A(15.7 \%$ vs. $5.0 \%)(P<0.001)$. The 
Table 5. Comparison of Injury Severity Score and severity classification between the two regions

\begin{tabular}{lccc}
\hline & $\begin{array}{c}\text { Group A (rural) } \\
(\mathrm{n}=1,484)\end{array}$ & $\begin{array}{c}\text { Group B (urban) } \\
(\mathrm{n}=323)\end{array}$ & P-value \\
\hline Injury Severity Score & $8.98 \pm 12.19$ & $4.62 \pm 8.30$ & $<0.001$ \\
Minor injury & $948(63.9)$ & $272(84.2)$ & $<0.001$ \\
Moderate injury & $303(20.4)$ & $35(10.8)$ & \\
Major injury & $142(9.6)$ & $9(2.8)$ & \\
Critical injury & $91(6.1)$ & $7(2.2)$ & \\
\hline
\end{tabular}

Values are presented as mean \pm standard deviation or number $(\%)$.

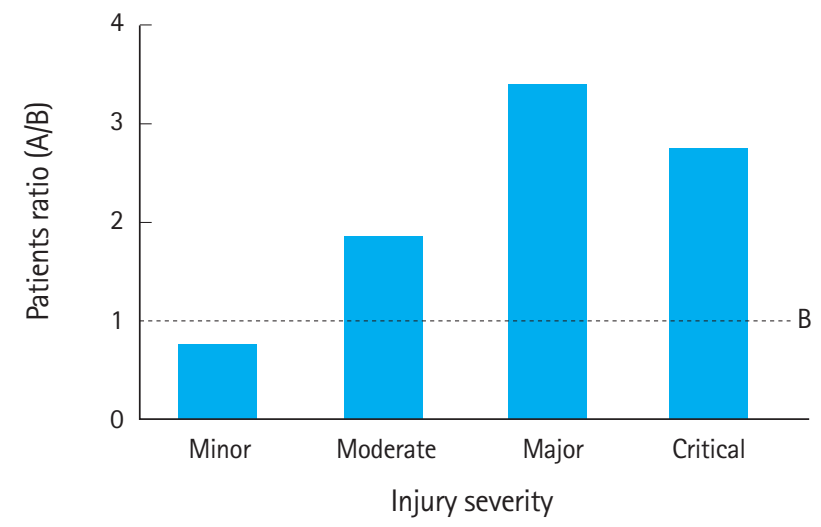

Fig. 1. Patient ratios in group $A$ compared to group $B$ are shown as $A / B$ by Injury Severity Score category. Minor severity was 0.76 , moderate severity was 1.89 , major severity was 3.43 , and critical severity was 2.77 . In the rural area, the proportion of minor severity patients is lower than that of the urban area, but the proportion of patients classified as moderate, major or critical severity is higher.

greater the injury severity, the greater the difference between groups was (Table 5 and Fig. 1).

\section{Variables associated with injury severity in both regions}

Four variables (time, vehicle, seat location, and seat belts) that differed significantly between the two regions were subjected to regression analysis in order to determine the variables that most affected injury severity. $R^{2}$ was 0.016 , and the explanatory power was low. Sitting on the driver's seat $(P=0.037)$ and wearing a seat belt $(P<0.001)$ were significantly associated with injury severity in both regions. Time and vehicle type did not show any significant correlations with injury severity (Table 6).

\section{DISCUSSION}

In South Korea, metropolitan areas account for $11.8 \%$ of the total land area and contain 50\% of the population. Central management functions, industries, and universities are concentrated in metropolitan areas. ${ }^{13}$ The city that group B was drawn from has
Table 6. Multiple regression analysis between the variables that differ between the two regions and the Injury Severity Score classification

\begin{tabular}{|c|c|c|c|c|c|}
\hline \multirow[t]{2}{*}{ Variable } & \multicolumn{2}{|c|}{$\begin{array}{l}\text { Unstandardized } \\
\text { coefficients }\end{array}$} & \multirow{2}{*}{$\begin{array}{c}\begin{array}{c}\text { Standardized } \\
\text { coefficients }\end{array} \\
\beta\end{array}$} & \multirow[t]{2}{*}{$\mathrm{t}$} & \multirow[t]{2}{*}{ P-value } \\
\hline & B & SE & & & \\
\hline Time & 0.021 & 0.045 & 0.012 & 0.468 & 0.640 \\
\hline \multicolumn{6}{|l|}{ Car type } \\
\hline Group 1 & -0.112 & 0.150 & -0.056 & -0.750 & 0.453 \\
\hline Group 2 & -0.018 & 0.154 & -0.009 & -0.117 & 0.907 \\
\hline Group 3 & Reference & & & & \\
\hline \multicolumn{6}{|l|}{ Seat location } \\
\hline Driver & 0.132 & 0.063 & 0.073 & 2.093 & 0.037 \\
\hline Assistant & 0.052 & 0.073 & 0.024 & 0.716 & 0.474 \\
\hline Others & Reference & & & & \\
\hline Seat belt use & 0.214 & 0.047 & 0.120 & 4.555 & $<0.001$ \\
\hline
\end{tabular}

$B$, unstandardized coefficients; $S E$, standard error.

the highest population density per unit area in Korea. Both regions were located on the East-West Expressway.

The rural city has a lower population and fewer annual ED visits than the urban city, but more patients were enrolled in the study. This could be explained by the fact that the number of hospitals in the urban city is larger than in the rural city, so there is likely to be a decentralized influence on the visiting patients. This is supported by the fact that the ratio of annual ED visits as a proportion of the city's overall population is lower in Bucheon compared to Wonju.

The two groups differed in the severity of injuries (Table 5). The risk of a mild injury was lower in the rural area, about 0.76 times that in the urban area; however, the risk of a severe injury was higher in the rural area by about 1.9 times for ISS $\geq 9,3.4$ times for ISS $\geq 15$, and 2.8 times for ISS $\geq 25$. These results suggest that injuries from traffic accidents are more serious in rural cities.

The degree of injury to a passenger in a traffic accident is affected by the characteristics of the vehicles, passengers, details of the accident, and the use of safety equipment. ${ }^{14,15}$ In this study, accident time, vehicle type, seat location, and seat belt use differed significantly between accidents in the rural and urban areas. The accidents in rural areas tended to occur more often in the daytime and involve large vehicles, passengers in a seat other than the driver's seat, and no seatbelt use. It is possible that even though the traffic burden in the urban area is greater regardless of the time of day as more drivers commute by car, seatbelts are worn more often due to police crackdowns and greater safety awareness.

Death, disability due to physical injury, and financial loss from traffic accidents are serious social burdens. Seatbelts are the only safeguards that prevent serious injury in passenger traffic accidents. ${ }^{16,17}$ In this study, not wearing a seat belt correlated significantly with a higher ISS (Table 3). In both regions, the rate of seat- 
belt use tended to be higher for patients in the driver's seat, and lower for those in the passenger seat or other seats (Table 4). In September 2018, it became mandatory for all passengers in South Korea to wear seatbelts, which will likely reduce overall traffic accident injury severity. However, it may be necessary to take additional measures to solve the traffic accident injury severity difference between regions because of the difference in the rate of seatbelt use between regions, regardless of which seat the passengers are in. Considering the lower rate of seatbelt use in the rural area, strengthening education and regulations related to safety devices such as seat belts may be very important.

This study had several limitations. First, it enrolled patients who visited an emergency medical center in one of two regions. Because patients who visited other medical institutions in the areas were not included, it is impossible to expand the results to all regional accidents. However, considering the roles of regional tertiary hospitals and medical emergency centers, our results are likely valid. Second, it is possible that patients with mild injuries did not visit a hospital. Because the regional center was selected as the target hospital, the selection error was believed to be small. Third, the study did not consider specific mechanical variables, such as collision speed. In human injury studies, variables such as speed cannot be measured easily because this requires cooperation between private sources of information and public institutions for specific vehicles.

In conclusion, our study found that the mean ISS was higher for accidents in a rural region than in an urban region, and these differences between the two regions increased with the ISS. Wearing seat belts was a major factor contributing to the difference in severity between the two regions studied. Further studies are needed to improve the regional difference in the severity of traffic accidents, and it is necessary to collect and analyze human injury data in more regions.

\section{CONFLICT OF INTEREST}

No potential conflict of interest relevant to this article was reported.

\section{REFERENCES}

1. Korean Statistical Information Service. Status of police receiving traffic accidents [Internet]. Daejeon: Statistics Korea; 2017 [cited 2019 Apr 3]. Available from: http://www.index. go.kr/potal/main/EachDtIPageDetail.do?idx_cd = 1614.

2. Niederdeppe J, Avery R, Miller EN. Alcohol-control public service announcements (PSAs) and drunk-driving fatal accidents in the United States, 1996-2010. Prev Med 2017;99:320-5.

3. Conner KA, Xiang H, Smith GA. The impact of a standard en- forcement safety belt law on fatalities and hospital charges in Ohio. J Safety Res 2010;41:17-23.

4. Kim SC, Lee KH, Lee WJ, Choi HY, Kim HJ. Pilot study on construction of a database for in-depth analysis of occupant injury and vehicle damage of domestic motor vehicle crash accidents. J Korean Soc Emerg Med 2012;23:315-26.

5. Kim S, Lee J, Youn Y. A study on the construction of the database structure for the Korea in-depth accident study. Trans Korean Soc Automot Eng 2014;22:29-36.

6. Jeon HJ, Kim SC, Lee KH. The effect that air bag deployment in car head-on collision on injury to driver. J Auto-Veh Saf Assoc 2018;10:13-9.

7. Lee HY, Lee JH, Jeon HJ, et al. Analysis of lower extremity injury mechanism centered on frontal collision in occupant motor vehicle crashes. J Auto-Veh Saf Assoc 2018;10:7-12.

8. Police Traffic Accident Statistics, Korean National Police Agency. Traffic accidents in 2017 [Internet]. Seoul: Korean National Police Agency [cited 2019 Apr 3]. Available from: https://www. police.go.kr/files/infodata/200436/2017/2017031.pdf

9. Wu Q, Zhang G, Zhu X, Liu XC, Tarefder R. Analysis of driver injury severity in single-vehicle crashes on rural and urban roadways. Accid Anal Prev 2016;94:35-45.

10. Yang MA. Introduction to the tool to classify the severity levels of injury patients. Cheongju: Korea Centers for Disease Control and Prevention; 2014.

11. Copes WS, Champion HR, Sacco WJ, Lawnick MM, Keast SL, Bain LW. The Injury Severity Score revisited. J Trauma 1988; 28:69-77.

12. Lee $M L$, Kim $H J$, Lee $K H$, et al. Analysis of driver behavior related to frontal vehicle collision direction. J Korea Acad-Ind Cooperation Soc 2016;17:530-37.

13. Son DG, Hur JW. A study on the effectiveness of the relocating public organization on the reduction of population concentration in the Seoul metropolitan area. J Korea Plan Assoc 2018;53:5-18.

14. Jo PS, Mok YH, Dam JS, Min CK. Estimation of driver injury severity in traffic collisions. J Transp Res 2017;24:1-15.

15. Kim JH. Human factors associated with the risk of traffic accidents among male and female drivers in Korea: policy implications for traffic accident prevention. J Saf Crisis manag 2012; 8:177-96.

16. Kim SA. Preventive effects of safety belt on the age in car traffic accidents. Seoul: Korean Society of Emergency Medicine; 2018.

17. Park WK, Bae JY, Seo JH. A study on the development of car accident prevention programs through the application of the evidence-based approach. Inst Humanit Soc Sci 2015;16:215-46. 